\title{
$M$ mode ultrasound and tissue Doppler imaging to assess diaphragm function in late onset Pompe disease
}

Paris Meng, Adam Ogna, Abdallah Fayssoil

Raymond-Poincaré hospital, APHP, Garches, France

\begin{abstract}
Late onset Pompe disease (LOPD) is an autosomal recessive lysosomal storage disease. Clinical features include skeletal muscles deficiency and diaphragm weakness. Clinical management relies on supportive treatment and mechanical ventilation in patents with chronic respiratory failure. $M$ mode ultrasound and sniff tissue Doppler imaging can be used to assess and to follow diaphragm function.
\end{abstract}

Key words: LOPD, diaphragm; ultrasound 


\section{Manuscript}

\section{Introduction}

Late onset Pompe disease (LOPD) is an autosomal recessive lysosomal storage disease. This disease is in relation with a defect in the activity of the glycogen degrading lysosomal enzyme, the alpha 1-4 glucosidase enzyme (GAA), causing glycogen accumulation and muscles weakness (1). Clinical features include skeletal muscles deficiency and diaphragm weakness. Clinical management relies on supportive treatment that includes enzyme replacement therapy and mechanical ventilation. Respiratory muscle monitoring is essential in this disease, since respiratory insufficiency and sleep disordered breathing are frequent in patients with LOPD and an important cause of morbidity $(2,3)$. Diaphragm, the main inspiratory muscle, has a crucial role for breathing during sleep. Diaphragm weakness is often associated with sleep-disordered breathing. Recently, ultrasound has been used to assess diaphragm weakness in LOPD (4). Here, using M mode ultrasound and tissue Doppler imaging (TDI) (5) , we report diaphragm weakness attested by a paradoxical motion during a sniff test in a patient with LOPD.

\section{Case report}

A 64-year-old female patient was referred to our unit for a cardiorespiratory evaluation because of dyspnea and orthopnea. She was treated with enzyme replacement therapy since 10 years because of LOPD. She had limb girdle weakness with waddling gait. The Walton score was at 3.The other clinical parameters were as follow: Body mass index at $26 \mathrm{~kg} / \mathrm{m} 2$, systolic blood pressure at $109 \mathrm{mmHg}$, diastolic blood pressure at $65 \mathrm{mmHg}$, and diurnal oxygen transcutaneous saturation at $100 \%$. Doppler Echocardiography showed a normal left ventricular ejection fraction (61\%) with normal cardiac loading and subnormal systolic arterial pulmonary pressure $(41 \mathrm{mmHg})$. We performed during the same exam a diaphragm exploration using ultrasound. From the subcostal view, we assessed the diaphragm motion using TM mode in rest and during a sniff maneuver, as previously described (5). We found a paradoxical diaphragm motion during a sniff maneuver of both the right $(-11 \mathrm{~mm})$ and the left hemi diaphragm (-18 mm), with $\mathrm{M}$ mode (figures 1 and 2). Using tissue Doppler imaging, we also found a negative and reduced peak velocity of diaphragm during the sniff maneuver, measured on the right hemi diaphragm $(-6 \mathrm{~cm} / \mathrm{s})$ and on the left hemi diaphragm $(-4 \mathrm{~cm} / \mathrm{s}$ ) (figures 3 and 4). Diaphragm weakness was confirmed by the decrease of maximal inspiratory pressure $(22 \mathrm{cmH} 20)$, the decrease of sniff inspiratory pressure $(29 \mathrm{cmH} 2 \mathrm{O})$ and the drop of the predicted value of respiratory forced vital 
capacity (VC) from upright to supine position (from $43 \%$ to $27 \%$ ). In the meantime, with transcutaneous capnometry, the patient disclosed nocturnal hypoventilation attested by an increase of the transcutaneous PCO2 (82\% of the registration time with pCO2 $>50 \mathrm{mmHg}$ ) and a decrease of transcutaneous PO2 (39\% of time with pO2<90\%). Non-invasive nocturnal ventilation was introduced to manage the respiratory failure.

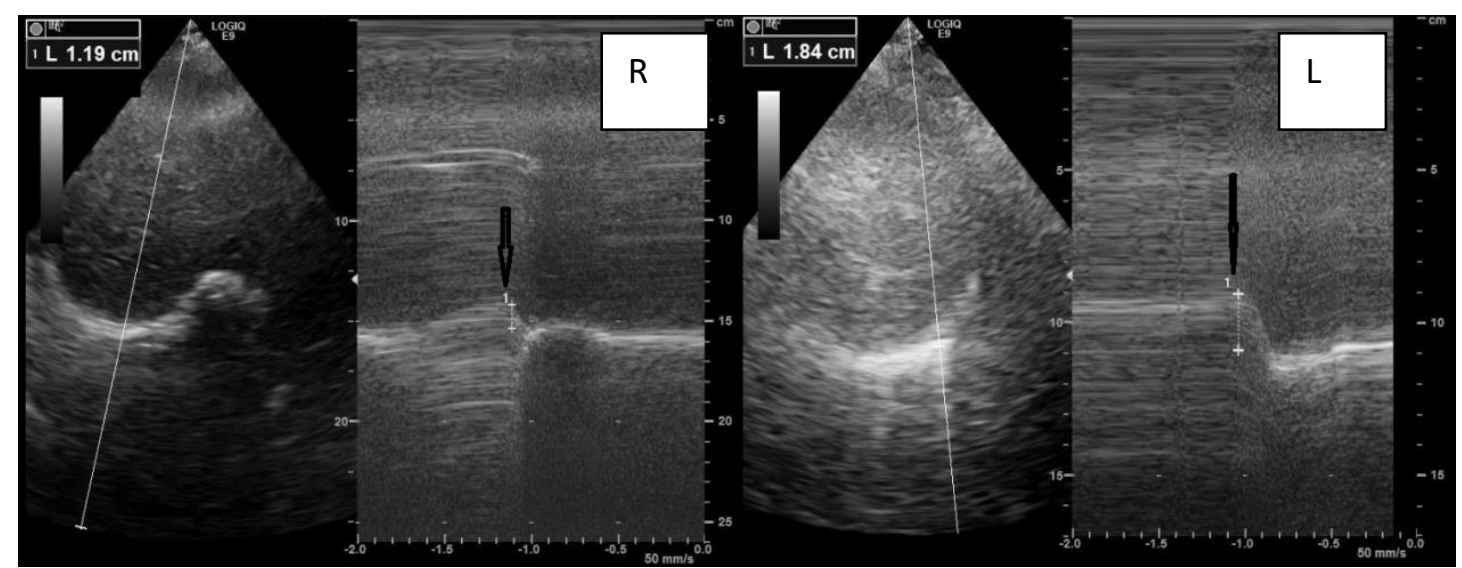

Figure 1 and figure 2: Right and left hemi diaphragm paradoxical displacement using $\mathrm{M}$ mode ultrasound during a sniff maneuver.

$R=$ right; L=left

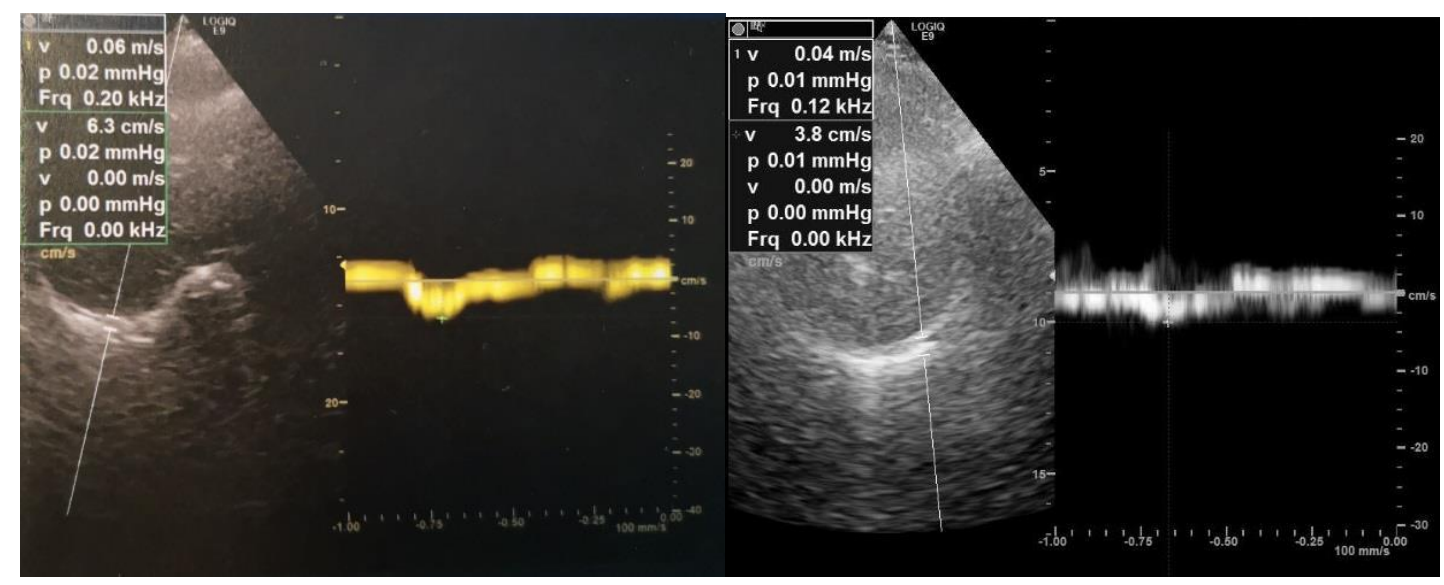

Figure 3 and figure 4 :

Right peak negative velocity $(-6 \mathrm{~cm} / \mathrm{s})$ and left peak negative velocity $(-0.4 \mathrm{~cm} / \mathrm{s})$ using tissue Doppler imaging coupled to a sniff maneuver. 


\section{Discussion}

We report this case, in which bedside diaphragm evaluation by ultrasound allowed to suspect diaphragm weakness with nocturnal hypoventilation as the cause of dyspnea and orthopnea, in a patient with LOPD. In LOPD, clinically relevant diaphragm weakness may develop even in patients with little peripheral muscular impairment, causing nocturnal hypoventilation, supine dyspnea aggravation, daytime hypercapnia, fatigue and excessive daytime sleepiness (3). Diaphragm weakness is often associated with limb girdle weakness (6). NIV has been shown to normalize gas exchange and improve respiratory status and symptoms, in this context $(1,7)$. Respiratory involvement in LOPD can be subtle and it is essential to monitor patients with repeated respiratory function tests, measuring vital capacity, maximal inspiratory pressure, and maximal expiratory pressure. The disease can affect not only the diaphragm, but also the upper airways and the other respiratory muscles (1). Classically, the drop of the VC from upright to supine is an indirect marker of diaphragmatic weakness (8). To assess the inspiratory muscle strength, sniff inspiratory nasal pressure and maximal inspiratory mouth pressure can be used. Sniff maneuver coupled with ultrasound can be used to selectively assess diaphragm function $(5,9)$. Regular respiratory function monitoring is crucial in LOPD. In fact, LOPD patients with a supine VC $<60 \%$ of predicted value have frequently sleep disordered breathing and nocturnal hypoventilation is frequent when VC is below $40 \%(10)$. M mode ultrasound and Tissue Doppler imaging may be applied in patients with LOPD to assess and monitor the diaphragm function, with the advantage of being applicable at the bedside, without the need of lung function facilities. In this case report, the paradoxical motion and the negative velocity of the diaphragm during the sniff manoeuver gave the clue to further investigate respiratory function, allowing to depict the presence of nocturnal hypoventilation. This finding highlights the potential application of ultrasound to monitor diaphragm in LOPD. Current guidelines recommend to introduce noninvasive ventilation in patients with LOPD relying on the values of blood gas exchange, MIP, FCV and sleep studies. Future studies will be necessary to assess the additive value of diaphragm ultrasound in this field.

\section{Conclusion}

In LOPD, bedside ultrasound may be used to screen for diaphragmatic dysfunction. In the presence of a diaphragm paradoxical motion or a negative TDI velocity during a sniff maneuver, nocturnal transcutaneous capnometry should be performed. 
Conflicts of interest: none

\section{References}

1) Mellies U, Lofaso F. Pompe disease: a neuromuscular disease with respiratory muscle involvement. Respir Med. 2009 Apr;103(4):477-84.

2) Boentert M, Dräger B, Glatz C, Young P. Sleep-Disordered Breathing and Effects of Noninvasive Ventilation in Patients with Late-OnsetPompe Disease. J Clin Sleep Med. 2016 Dec 15;12(12):16231632

3) Boentert M, Karabul N, Wenninger S, Stubbe-Dräger B, Mengel E, Schoser B, Young P. Sleep-related symptoms and sleep-disordered breathing in adult Pompe disease. Eur J Neurol. 2015 Feb;22(2):369-76

4) Spiesshoefer J, Henke C, Kabitz HJ, Brix T, Görlich D, Herkenrath S, Randerath W, Young P, Boentert M. The nature of respiratory muscle weakness in patients with late-onset Pompe disease. Neuromuscul Disord. 2019 Jun 22.

5) Fayssoil A, Nguyen LS, Ogna A, Stojkovic T, Meng P, Mompoint D, Carlier R, Prigent H, Clair B, Behin A, Laforet P, Bassez G, Crenn P, Orlikowski D, Annane D, Eymard B, Lofaso F. Diaphragm sniff ultrasound: Normal values, relationship with sniff nasal pressure and accuracy for predicting respiratory involvement in patients with neuromuscular disorders. PLoS One. 2019 Apr 24;14(4):e0214288

6) van der Beek NA, van Capelle CI, van der Velden-van Etten KI, Hop WC, van den Berg B, Reuser AJ, van Doorn PA, van der Ploeg AT, Stam H. Rate of progression and predictive factors for pulmonary outcome in children and adults with Pompe disease. Mol Genet Metab. 2011 Sep-Oct;104(1-2):12936

7) Mellies U, Stehling F, Dohna-Schwake C, Ragette R, Teschler H, Voit T. Respiratory failure in Pompe disease: treatment with noninvasive ventilation. Neurology. 2005 Apr 26;64(8):1465-7.

8) Fromageot C, Lofaso F, Annane D, Falaize L, Lejaille M, Clair B, Gajdos P, Raphäl JC. Supine fall in lung volumes in the assessment of diaphragmatic weakness in neuromuscular disorders. Arch Phys Med Rehabil. 2001 Jan;82(1):123-8.

9) Iandelli I, Gorini M, Misuri G, Gigliotti F, Rosi E, Duranti R, Scano G. Assessing inspiratory muscle strength in patients with neurologic and neuromuscular diseases : comparative evaluation of two noninvasive techniques. Chest. 2001 Apr;119(4):1108-13.

10) Kishnani PS, Steiner RD, Bali D, Berger K, Byrne BJ, Case LE, Crowley JF, Downs S, Howell RR, Kravitz RM, Mackey J, Marsden D, Martins AM, Millington DS, Nicolino M, O'Grady G, Patterson MC, Rapoport DM, Slonim A, Spencer CT, Tifft CJ, Watson MS. Pompe disease diagnosis and management guideline. Genet Med. 2006 May;8(5):267-88 